\title{
La investigación
}

\section{científica \\ en España}

Daniel Tena-Parera, Universitat Autònoma

de Barcelona, Daniel.tena@uab.cat

\section{Informe IUNE 2018: actividad investigadora de las universidades españolas}

Alianza 4 Universidades (A4U): Universitat Autònoma de Barcelona (UAB), Universidad Autónoma de Madrid (UAM), Universidad Carlos III de Madrid (UC3M) y Universitat Pompeu Fabra (UPF), info@inaecu.com; Observatorio IUNE, Julio 2018
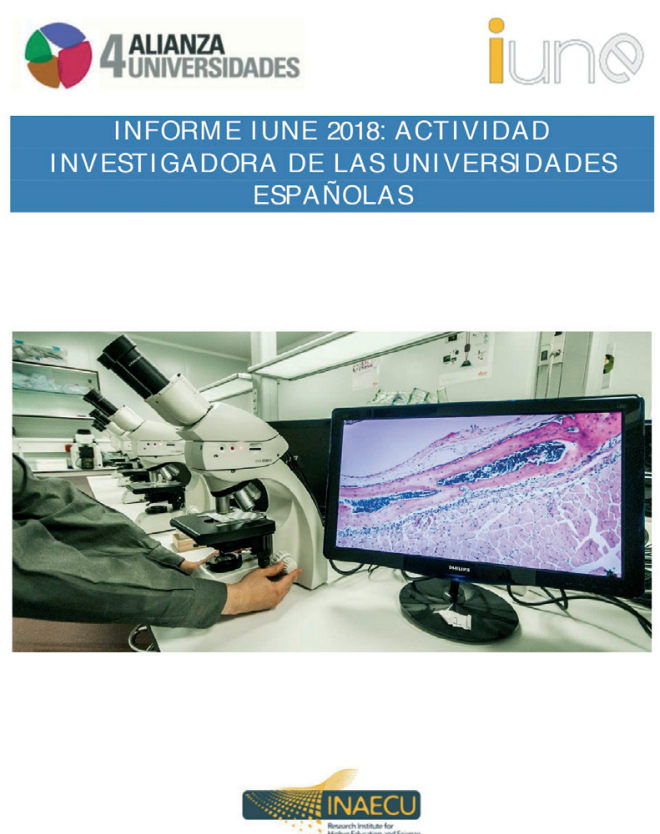

Se da noticia de la publicación del informe que analiza la investigación científica en España desde distintas dimensiones relacionadas con el profesorado, el reconocimiento, la actividad científica, la innovación, la competitividad y la capacidad formativa y, a partir de una amplia batería de indicadores, se realiza el seguimiento de la I+D+i universitaria española desde 2007 hasta 2016.

\section{Palabras Clave}

Investigación; universidad; España; IUNE

Scientific research in Spain

News is given of the publication of the report that analyzes scientific research in Spain from different dimensions related to the teaching staff, the recognition, the scientific activity, the innovation, the competitiveness and the formative capacity and, from a wide battery of indicators, the monitoring of the Spanish university $R+D+i$ is made from 2007 until 2016.

Keywords

Research; university; Spain; IUNE 
EI Diseño gráfico y la Investigación científica. La investigación científica en diseño debe mejorar y debe apostar por reivindicarse frente a las líneas hegemónicas de la investigación científica en España. Si se quiere dotar al área de conocimiento con doctores que cumplan con las funciones de hacer avanzar el conocimiento del objeto de estudio y la consecuente transferencia de conocimiento, se debe, sin pretender emular, dejarse influir por las áreas punteras en la investigación científica. No hacerlo es ocultarse bajo la aparente especificidad del ámbito del diseño gráfico. No hacerlo es condenar al diseño gráfico a ser un ámbito menor del conocimiento. No se trata de reproducir defectos, que sin duda los hay; se trata de encontrar los convencionalismos propios del área de conocimiento.

Así pues y con este objetivo, creemos interesante promocionar aquí la nueva edición del Observatorio IUNE sobre la investigación científica en España. Ésta se suma a las anteriores, todas consultables en la web del IUNE. Desde este observatorio se ha puesto al servicio de todos los investigadores un estudio que analiza desde distintas dimensiones relacionadas con el profesorado, el reconocimiento, la actividad científica, la innovación, la competitividad y la capacidad formativa y, a partir de una amplia batería de indicadores, se realiza el seguimiento de la $1+D+i$ universitaria española desde 2007 hasta 2016.
El IUNE inició su andadura en el año 2012, coordinado por el Laboratorio de Estudios Métricos de la Información (LEMI) de la Universidad Carlos III de Madrid, en el marco de la Alianza 4 Universidades (A4U) integrada por las universidades Autónoma de Madrid, Autónoma de Barcelona, Carlos III de Madrid y Pompeu Fabra.

La obtención de datos procede de fuentes oficiales, como la Comisión Evaluadores de la Actividad Investigadora (CNEAI), la Fundación Española para la Ciencia y la Tecnología (FECYT), el Instituto Nacional de Estadística (INE), el Centro para el Desarrollo Técnico Industrial (CDTI), la Red OTRI (CRUE), la Oficina Española de Patentes y Marcas (OEPM), el SIIU (Sistema de información integral universitaria) y la plataforma Web of Science (WoS) para los datos relativos a publicaciones.

Además, en este informe que recoge los resultados obtenidos en la década analizada, a partir de los distintos indicadores utilizados y tres nuevos informes sobre coautoría e hiperautoría, mediana de autores por documento por categoría WOS y año y promedio de autores por documento por categoría WOS y año (SUE 2007-2016). Para más información consultar: (www.iune.es);

http://www.informes.iune.es/Informe $\% 20$ IUNE\%202018.pdf; http://www.iune.es/es_ES/ informes. 